\title{
Lebanese Student's Experience of Benefits of High Fidelity Simulation in Nursing Education: A Qualitative Approach
}

\author{
Mirna A. Fawaz' , Ayman M. Hamdan-Mansour² \\ ${ }^{1}$ Adult Health Nursing, Nursing Department, Faculty of Health Sciences, Beirut Arab University, Beirut, Lebanon \\ ${ }^{2}$ Mental Health Nursing, Community Health Department, School of Nursing, the University of Jordan, Amman, Jordan \\ Email:mirnafawaz@bau.edu.lb, a.mansour@ju.edu.jo
}

How to cite this paper: Fawaz, M.A. and Hamdan-Mansour, A.M. (2016) Lebanese Student's Experience of Benefits of High Fidelity Simulation in Nursing Education: A Qualitative Approach. Open Journal of Nursing, 6, 853-862.

http://dx.doi.org/10.4236/ojn.2016.610084

Received: October 2, 2016

Accepted: October 23, 2016

Published: October 26, 2016

Copyright $\odot 2016$ by authors and Scientific Research Publishing Inc. This work is licensed under the Creative Commons Attribution International License (CC BY 4.0).

http://creativecommons.org/licenses/by/4.0/ c) (i) Open Access

\begin{abstract}
Background: Simulation is perceived as an important part to the nursing clinical educational experience since it can offer a safe learning environment for the students' clinical practice. Objective: The purpose of this study was to explore the Lebanese student's experience of benefits of high fidelity simulation in nursing education. Design: A qualitative study using open-ended questionnaire. Setting: This study was implemented at private university in Lebanon between January and April 2015. Participants: A purposive sample was sought from those who have a simulated experience. Methods: Qualitative data were collected via interviews and analysed using a thematic approach. Findings: Four major themes were identified: "Bridging Theory to Clinical Practice", "Developing Critical Thinking and Decision-making", "Practicing Safely Leads to Enhancing Confidence", "Teamwork Spirit and students' motivation to earn and practice more". Conclusion: Simulation was found to be an acceptable learning strategy for novice nursing students. The use of simulations is a useful and effective learning strategy. Students with a higher positive attitude towards the simulation experience displayed better learning outcomes. Thus, the integration of simulation into the learning experience of nursing students will bridge the gap between theory and practice; enhance their critical thinking and motivation aptitudes along with traditional clinical practice by sparing them a safe milieu.
\end{abstract}

\section{Keywords}

High-Fidelity Simulation, Nursing Students, Personal Experience

\section{Introduction}

Nursing educators are challenged to implement teaching techniques that enhance the 
clinical performance of students while reinforcing their clinical judgment and critical thinking skills [1]. As a matter of fact, in its position statement on teaching modernization, the National League for Nursing (2003) stated that nurse pedagogues have to make "learning environment that facilitate students' critical thinking [and] self-reflection" and train "graduates for practice in a complex, dynamic health care environment" [2]. This challenge is powered by advances in technology; expanded levels of patient acuity, issues identified by patient safety, and mandates by accreditation agencies [3] [4]. This would be a response and proposed solution for another global nursing problem; the shortage of nursing workforce [5] [6].

Positive learning experience in clinical practice can be an establishment for attaining successful practice. This can help supporting students to become qualified nurses [7] [8]. In clinical practice, the learning experience needs to include adequate preparation for practice, the hospital atmosphere and healthy communication-based relationship between the students and their clinical preceptors. Exchange of learning is a complex and systemic process that is affected by various elements. For instance, the educational design and working environment do affect student's ability to perform in the clinical training settings [9]. Such factors are assumed also to negatively influence intrinsic motivation for learning and knowledge acquisition among nursing students [10]. While real and hands on teaching for nursing students seems beneficial and have significant impact on their clinical competency, workplace environment and risks concerning clinical demonstration on patients would urge finding less risky solution with equal benefits. Posing control over nursing students' clinical training had invited using high fidelity simulation into clinical training [11] [12]. This will not be a substitutional strategy, and rather, a preparatory stage.

Simulation is identified as an innovative educational approach that attempts to mimic vital aspect of clinical cases [13], and as a pedagogical methodology, changes or strengthens experiences that mimics concepts of the genuine world in an interactive method [14]. A simulation-based learning strategy is a selection of planned activities that correspond to present or prospective situations in education and practice. It permits students to improve information skills and behaviors, evaluate and react to authentic scenarios in simulated settings by case studies [15]. This type of safe milieu could support student learning in simulation, which is often recognized as a "safe" learning setting. The ability of the student to integrate knowledge, skill, and judgment elevates students' autonomy to make assessments and develop critical thinking, which lead to competent decision-making. The greater values of using the HFS are also concerned with the creation of reflective learning environment for students that enable them to control their anxiety to newly learned experiences prior to their entry into practice [16].

Educators, nursing graduates and healthcare employers stand to benefit from the blending of simulation with clinical hours; nursing educators gain added flexibility and autonomy in the design, development and evaluation of learning experiences and curricula. Graduate nurses can integrate the immediacy and real word quality of simulation with the discipline and rigor of traditional clinical hours. Moreover, understanding 
the mechanisms of how simulation cultivates transfer of learning may encourage educators to use simulation more frequently as a teaching and learning technique. Thus, nursing students obtain the skills of patient care, professional communication, and the capabilities of problem-solving, psychomotor skills, and critical thinking. They also improve their socialization and professional role confidence [17].

In the light of the stated advantages, High Fidelity Simulation activities has been adopted as a part of the clinical practice of first year baccalaureate nursing (BSN) program in one nursing school in Lebanon. Nevertheless, to date, there is no qualitative data that explores the perception of BSN students of employing HFS as part of their program. Therefore, the purpose of this study is to investigate the Lebanese nursing student's perception of benefits of simulation in nursing education.

\section{Material and Methods}

Design: This study is part of larger study aimed at exploring the impact of high-fidelity simulation on the development of clinical judgment and motivation among Lebanese nursing students. This study used a phenomenological approach. Data were collected from one of the largest universities in the capital city Beirut through interviewing the students individually, using unstructured interview. Beirut Arab University (BAU), situated in the vital capital of Lebanon, is a center of culture and education. With more than 300 higher educational programs, BAU offers a productive educational environment to approximately 15,000 students every year in Lebanon and abroad. BAU has been committed, since its establishment in 1960, to offer outstanding educational programs and to provide an embracing environment for academic creativity and the development of leadership skills, instilling the concept of social responsibility, while respecting diversity and multicultural understanding. BAU comprise 10 faculties, 44 undergraduate programs, 95 postgraduate programs. 9037 undergraduate students, 1199 postgraduate students were registered per year. Data collection started in January 2015 until April 2015, by the primary researcher who is a lab and clinical instructor in the faculty of Nursing. Prior to data collection, the primary investigator obtained ethical approval for conducting the study.

Sample and setting: A purposive sample was recruited from the first year undergraduate nursing students with no prior simulation experience. Eight nursing students, out of a total 24 students representing the whole class, were interviewed from one major university in the capital city Beirut. Using a calculated effect size of 0.30 based on assumption of expected difference of squared standard deviation of 1.0 and a maximum expected difference in the confidence interval of 0.5 , the power of 0.80 results in a sample of 24 subjects per group. Inclusion criteria included: 1) nurse student registered in first adult health nursing course, 2) nurse student completed the simulation intervention and be willing to share personal experiences related to simulation. Students were provided with the consent form, which was explained, to read and sign prior to the commencement of the interviews. Prior to signing consent forms, the researcher answered students' questions, and assured them of the confidentiality and privacy of the 
study. Students were informed that they will have the right to withdraw from the research at any point and that their participation is voluntarily.

\section{Data Collection}

Data were collected using unstructured interviews with students after the simulation and after clinical training. The purposive sizes of the samples among those who agreed to participate in the qualitative part that took the form of a focus group. This approach provides significant in-depth information of simulation experience. Willing students participated in two focus group interviews conducted a week after the students completed their clinical placement experience. The purpose of the first focus group interview was to gain an understanding of the students' perception of high-fidelity simulation, their experience of participating in the simulation exercise, and to explore their perceptions of impact of HFS on their learning and clinical training. In the second focus group, students were asked to reflect broadly on their practice experience in light of participating in the high-fidelity simulation-based learning scenario. Prior to signing consent forms, the researcher answered participants' questions, and assured them of the confidentiality and privacy of the study. The focus group session was in the Nursing Simulation Lab, where the participating students observed and debriefed simulation experiences in their clinical courses. The location for the focus group was carefully chosen, with the intent of bringing students into the setting where they exhibited their simulation observations and debriefing. The time of the focus group was arranged according to the convenience of the students. Data collection was conducted by using student's interviews. An unstructured interview was used in this study to encourage participants to produce their own experience; open-ended questions encouraged them to build-up and elaborate their own narrative. The Co-researcher (faculty member who teaches in the simulation lab) maintained records and noted the session. To avoid feeling that some interviewees are put off by the presence of the tape-recorder, the researcher assured them that the recording is only for the research purpose and nobody except her would have access to the interview tape-records and will be kept in a closed cabinet at the Faculty of Health Sciences-Nursing Department, Beirut Arab University. The interviews lasted for 2 hours. The interviews were recorded and transcribed verbatim. After review, the themes of meaningful learning, evidenced by the students were identified.

\section{Data Transcribing, Coding and Analysis}

Interviews were audio-taped and transcribed verbatim. Detailed field notes were reviewed and typed promptly. Discussions among the research team that were related to coding, interpreting, and conceptualizing of the data were documented in memo form for auditability. The researcher used these questions to serve as prompts in order to explore the Lebanese student's experience of benefits of high fidelity simulation in nursing education.

1) How did simulation help to develop your clinical judgment abilities? 
2) Was simulation helpful or not in your clinical practical experiences? How?

3) Thinking through the four phases of the Clinical Judgment Model, how did simulation help you to notice what was going on with the patient?

4) How did your experience with simulation improve or reduce from your clinical experiences?

5) During what part of the HFS experience did you mostly learn concerning clinical judgment?

6) Is there anything else you would like to discuss that we haven't covered or asked about regarding the simulation experience?

The interviews were recorded and transcribed verbatim. Each account was read and reread using the participants own words. Significant statements were highlighted and the meaning of statements was extracted. The qualitative analysis included reviewing all interviews' transcripts and coding any behaviors and quotes that are related to students' perception. The transcribed data was then analyzed for further investigation. The transcribed documents were coded and categories of responses were identified. Content analysis was used to address qualitative data available from the group session's discussions. Codes were then collapsed into categories to identify student's perceptions.

\section{Trustworthiness}

Trustworthiness of the results was enhanced through method triangulation. Two unstructured methods, namely focus group interviews and documents, were used to collect data on the same phenomenon [18]. Furthermore, the credibility of the facilitator raised the trustworthiness of the results. Dependability was heightened by the supporting and contrasting literature corroboration in the discussion of the results. The dense description of the process and results allow for transferability [18].

\section{Results}

The descriptive analysis showed that the majority of the samples in the intervention group were females $(65.4 \%)$ while male students formed $34.6 \%$. The mean age for the sample was 18.8 years. The age of the students ranged from 18 to 21 years. The analysis of the accounts resulted in the following four major themes: (1) Bridging theory to clinical practice, (2) Developing critical thinking and decision-making, (3) Practicing safely leads to enhancing confidence, and (4) Developing teamwork spirit and students' motivation to earn and practice more. All themes were identified with their frequencies and a quotation was taken for each theme (minor) showing how it is expressed verbatim (see Table 1).

Bridging theory to clinical practice: The HFS provides the students with an exceptional opportunity to practice realistic scenarios in the learning in situ without any harmful risk to patients. Students acknowledge how the HFS can advance the "practice theory linkage" as they gain a wider picture of patients' conditions.

Developing critical thinking and decision-making: Students perceived that simulation allowed them to build up their theoretical knowledge, and permit them to 
Table 1. Students' perceptions of e simulation: an exemplary quotes.

\begin{tabular}{|c|c|}
\hline Themes & Selected exemplary quote \\
\hline \multirow[t]{2}{*}{$\begin{array}{l}\text { Bridging Theory to } \\
\text { Clinical Practice }\end{array}$} & $\begin{array}{l}\text { "The real opportunity that we passed through was when we connect what } \\
\text { we had learned from simulation to advance our clinical experience. Just I } \\
\text { will remember what I did in the simulation laboratory and I will follow the } \\
\text { same when I'm dealing with the real patient as if it was not my first time in } \\
\text { doing the procedure or diagnosing the case." } \\
\text { "The HFS laboratory gave me the sense of hospital atmosphere } \cdots \text { it contains } \\
\text { the same equipment, and indeed, with the scenario that the instructor used, } \\
\text { I felt that I'm in real-life situation". } \\
\text { "I went back over my notes that I took in the lecture and had a look at the } \\
\text { way that I can deal with a CHF patient, actually it was a good experience to } \\
\text { link the lectures to simulation and the simulation to clinical practice". } \\
\text { "from this training } \cdots \text { from the simulation } \cdots \text { I can learn how to assess a } \\
\text { patient's condition } \cdots \text { it is like a realistic method to practice nursing } \\
\text { procedures and patients diagnoses". }\end{array}$ \\
\hline & $\begin{array}{l}\text { "The simulator permitted me to convert what I learned } \cdots \text { the theory } \cdots \text { into } \\
\text { practice and work with my hands } \cdots \text { I'm feeling that I started to be a } \\
\text { nurse } \cdots \text { beautiful feeling for the first time". }\end{array}$ \\
\hline $\begin{array}{l}\text { Developing Critical } \\
\text { Thinking and } \\
\text { Decision-making }\end{array}$ & $\begin{array}{l}\text { "Simulation imitated what I have been taught in the classroom". } \\
\text { "I implemented the knowledge that I have learned previously to interpret } \\
\text { the data, it helped me to realize the needs of the patients identified the ab- } \\
\text { normal signs and symptoms". }\end{array}$ \\
\hline $\begin{array}{l}\text { Practicing Safely Leads } \\
\text { to Enhancing } \\
\text { Confidence }\end{array}$ & $\begin{array}{l}\text { "it is safer for me to do mistakes here on the manikin for several times than } \\
\text { to do them out there in the real hospital life" } \cdots \text { this experience gave me the } \\
\text { confidence to face the reality of patients in their units". } \\
\text { "simulation helped me more to be more confident and trust my abilities". } \\
\text { "what I went through in the scenario offered me confidence } \cdots \text { I already } \\
\text { recognized the sequence of the steps that I have to perform in advance } \cdots \text { it } \\
\text { augmented my confidence in practice }\end{array}$ \\
\hline $\begin{array}{l}\text { Developing Teamwork } \\
\text { Spirit and Students' } \\
\text { Motivation to Earn and } \\
\text { Practice More }\end{array}$ & $\begin{array}{l}\text { "the group work forced me to discuss some issues in the group, introduce } \\
\text { and pose my ideas and seek help from-my classmates. Negotiations were } \\
\text { going on throughout the group work between the group members". } \\
\text { "It really motivated me to work hard as I felt self-confident to work between } \\
\text { the group members where no fear from harm to human beings existed. This } \\
\text { was a beneficial experience because it is like a real working experience } \\
\text { within the health care teams". }\end{array}$ \\
\hline
\end{tabular}

recognize what was happening with the patients so that they can make an appropriate judgment. Learning in context that gives the students the impression of working in a hospital atmosphere as well as reflecting on practice with immediate discussion in a precise plan are touted to be as means for practicing critical thinking.

Practicing safely leads to enhancing confidence: Students have the chance to practice what they have learned in the classroom without any risk to the patient as they can see the techniques and learn from their mistakes.

Developing teamwork spirit and students' motivation to earn and practice more: Students described this kind of learning experiences as a new method to enhance their teamwork that leads them to increase their motivation. The productive teamwork that was shown in communication, negotiation, and cooperation between the students was a positive learning experience. 


\section{Discussion}

Themes abstracted in this study displayed a favorable experience with the simulation offering the sentiments that High-Fidelity Simulation (HFS) has become a prerequisite to the start of actual clinical practice.

Bridging theory to clinical practice was the most repeated theme. Students reported that they could transfer their classroom knowledge because they can apply their knowledge and skills from simulated work setting in the training. This indicates that they were able to correlate between different theoretical views and implement the earned information in their clinical practice in the real-life clinical area. Leigh (2008) describes simulation as the vehicle for translating classroom knowledge into a safe "clinical" learning environment [19].

Developing critical thinking and decision-making was reported many occasions by the students indicating that clinical simulation enabled them to employ the theoretical information and skills presented in the classroom in their clinical practice and specifically enhanced their sense of clinical judgment. Critical thinking and decision-making are exercised during simulation and imply that students are capable to convey their classroom learning in clinical practice simulation. Thus, High Fidelity Simulation (HFS) offered students the opportunity to strengthen their theoretical knowledge enabling them to perceive what the patient was encountering in order to formulate a suitable judgment. Kaddoura (2015) asserted that simulation cultivates clinical judgment, self-confidence, and theory-practice merging dexterity [20].

Practicing safely leads to enhancing confidence, the third theme, was repeated also in many occasions. Students perceived that HFS is an essential technique of learning that can promote self-confidence. Simulation serves as a highly effective strategy for developing confidence and entry into practice creating a learning environment that promotes safety, knowledge, skills and confidence. Kaddoura (2015) reported that HFS has been displaying an affirmative outcome on increasing nursing students' confidence attitudes [20].

The fourth theme Developing teamwork spirit and students' motivation to earn and practice more, indicates that nursing students were empowered as they were perceived as learners and team members during their clinical experience. Students recognized High Fidelity Simulation as a helpful technique of learning that promotes collaboration and teamwork. Receiving moral support and constructive feedback as well as being able to cooperate with others on directed acts improved their sense of motivation and facilitated learning in clinical practice. On the other hand, motivation to learn and to transfer classroom knowledge is strengthened when students encounter patients in the clinical practice with conditions similar to those portrayed in simulation. The fact that students enjoy the learning experience contributes to the motivation to be transferred. It has been reported that nursing students, similar to working nursing staff, were empowered when perceived as learners and member of team during their clinical experience [21] [22]. Students thus prefer to learn within teams rather than merely observing, as they need to grasp knowledge and correlate it in clinical practice. Thus, working 
through teamwork is vital to prepare future student nurses in various interpersonal relationships within different healthcare settings [23] [24].

\section{Limitations of the Study}

The study had a comparatively small sample size which hinders the generalization of results. It is recommended that similar studies be carried out at various settings and with large sample size.

\section{Conclusions}

Qualitative data were collected through two focus group interviews and standard evaluation forms. The open-ended question on the form was the same as the one asked during the focus group interviews. Open coding of the data revealed four themes, namely bridging theory to clinical practice, developing critical thinking and decision-making, practicing safely leads to enhancing confidence, and developing teamwork spirit and students' motivation to earn and practice more. The participating students perceived simulation to be a tool that bridges the theory-practice gap. They mentioned that they could apply their theoretical knowledge; thus, transfer of learning occurred. Confidence to engage in delivering care to patients during work-integrated learning augmented since the participants perceived what they were to expect and what was expected from them.

Experiencing a High-Fidelity Simulation learning opportunity is a strong motivator to learn and to apply in practice what has been learnt in the classroom. It is therefore equally important in the educational design factor because it spotlights the pertinence of the content in the spectrum of courses that is integrated into a nursing degree program. Moreover, HFS enables students to productively participate with the learning material which, according to the respondents of this study, supports the retention of knowledge.

\section{References}

[1] Gaba, A. (2015) Teaching Clinical Judgment: A Review with Consideration of Applications for Health Professions. The Open Nutrition Journal, 9, 53-56.

[2] National League for Nursing. Position Statement (2003) Innovation in Nursing Education: A Call to Reform. http://www.nln.org/docs/default-source/about/archived-position-statements/innovation-in -nursing-education-a-call-to-reform-pdf.pdf?sfvrsn $=4$

[3] Halabi, J. and Hamdan-Mansour, A. (2012) Attitudes of Jordanian Nursing Students towards Nursing Research. Journal of Research in Nursing, 17, 363-373. http://dx.doi.org/10.1177/1744987110379782

[4] Hamaideh, S. and Hamdan-Mansour, A. (2014) Psychological, Cognitive, and Personal Variables That Predict College Academic Achievement among Health Sciences Students. Nurse Education Today, 34, 703-708. http://dx.doi.org/10.1016/j.nedt.2013.09.010

[5] Jeffries, P.R. and Rizzolo, M. (2006) NLN-Laerdal Project Summary Report, Designing and Implementing Models for the Innovative Use of Simulation to Teach Nursing Care of Ill Adults and Children: a National Multi-Site Study. National League for Nursing, New York. 
[6] Tri-Council for Nursing (2007) Letter to the National Governor's Association, 8/13/07. http://www.nln.org/docs/default-source/advocacy-public-policy/nga final.pdf?sfvrsn=2

[7] Yang, H., Thompson, C. and Bland, M. (2012) The Effect of Clinical Experience, Judgment Task Difficulty and Time Pressure on Nurses' Confidence Calibration in a High-Fidelity Clinical Simulation. BMC Medical Informatics and Decision-Making, 12, 113. http://dx.doi.org/10.1186/1472-6947-12-113

[8] Fawaz, M. and Hamdan-Mansour, A. (2016) Effect of Using HFS on Motivation and Clinical Judgment among Nursing Students in Lebanon. Nurse Education Today, 46, 36-42. http://dx.doi.org/10.1016/j.nedt.2016.08.026

[9] Botma, Y. (2014) Nursing Student's Perceptions on How Immersive Simulation Promotes Theory-Practice Integration. International Journal of Africa Nursing Sciences, 1, 1-5. http://dx.doi.org/10.1016/j.ijans.2014.04.001

[10] Kudo, Y., Hayashi, S., Yoshimura, E., Shibuya, A. and Aizawa, Y. (2013) Nursing Students' Learning Motivation toward Technical Knowledge and Their Ethics Regarding Patients' Rights. The Tohoku Journal of Experimental Medicine, 230, 33-42.

http://dx.doi.org/10.1620/tjem.230.33

[11] Hamdan-Mansour, A., Constantino, R, Farrell, M., Doswell, W., Gallagher, M.E., Safadi, R. Shishani, K. and Banimustafa, R. (2011) Evaluating the Mental Health of Jordanian Women in Intimate Partner Abuse. Issues in Mental Health Nursing, 32, 614-623. http://dx.doi.org/10.3109/01612840.2011.580494

[12] Almadi, T., Cathers, I., Hamdan Mansour, A. and Chow, C.M. (2012) The Association between Work Stress and Inflammatory Biomarkers in Jordanian Male Workers. Psychophysiology, 49, 172-177. http://dx.doi.org/10.1111/j.1469-8986.2011.01296.x

[13] Buckley, T. and Gordon, Ch. (2011) The Effectiveness of High-Fidelity Simulation on Medical-Surgical Registered Nurses' Ability to Recognize and Respond to Clinical Emergencies. Nurse Education Today, 31, 716-721. http://dx.doi.org/10.1016/j.nedt.2010.04.004

[14] Gaba, D.M. (2004) The Future Vision of Simulation in Health Care [Electronic Version]. Quality and Safe Health Care, 13, i2-i10. http://dx.doi.org/10.1136/qshc.2004.009878

[15] Meakim, C., Boese, T., Decker, S., Franklin, A.E., Gloe, D., Lioce, L. and Borum, J.C. (2013) Standards of Best Practice: Standard I: Terminology. Clinical Simulation in Nursing, 9, 3-11. http://dx.doi.org/10.1016/j.ecns.2013.04.001

[16] Morgan, R. (2006) Using Clinical Skills Laboratories to Promote Theory-Practice Integration during First Practice Placement: An Irish Perspective. Journal of Clinical Nursing, 15, 155-161. http://dx.doi.org/10.1111/j.1365-2702.2006.01237.x

[17] Karayurt, O., Mert, H. and Beser, A. (2009) A Study on Development of a Scale to Assess Nursing Students' Performance in the Clinical Settings. Journal of Clinical Nursing, 18, 1123-1130. http://dx.doi.org/10.1111/j.1365-2702.2008.02417.x

[18] Polit, D.F. and Beck, C.T. (2004) Nursing Research: Principles and Methods. 7th Edition, Lippincott Williams \& Wilkins, Philadelphia.

[19] Leigh, G.T. (2008) High Fidelity Patient Simulation and Nursing Students' Self-Efficacy: A Review of the Literature. International Journal of Nursing Education Scholarship, 5, 1-17. http://dx.doi.org/10.2202/1548-923x.1613

[20] Kaddoura, M., Vandyke, O., Smallwood, Ch. and Gonzalez, K. (2015) Perceived Benefits and Challenges of Repeated Exposure to High-Fidelity Simulation Experiences of First Degree Accelerated Bachelor Nursing Students. Nurse Education Today, 36, 298-303. http://dx.doi.org/10.1016/j.nedt.2015.07.014

[21] Matchim, Y. and Kongsuwan, W. (2015) Thai Nursing Students' Experiences When At- 
tending Real Life Situations Involving Cardiac Life Support: A Phenomenological Study. Nurse Education Today, 35, 1186-1189. http://dx.doi.org/10.1016/j.nedt.2015.05.010

[22] Hamdan-Mansour, A., Marmash, L., Elayyan, R. and Hyarat, S. (2014) Difference in Perception between Nurses and Patients Related to Patients' Health Locus of Control. International Journal of Nursing Practice, 20, 242-249. http://dx.doi.org/10.1111/ijn.12132

[23] Hamdan-Mansour, A.M., Al Abeiat, D.D., Alzoghaibi, I.N., Ghannam, B.M. and Hanouneh, S.I. (2015) Psychosocial and Sociodemographic Correlates of Life Satisfaction among Patients Diagnosed with Cancer in Jordan. Journal of Cancer Education, 30, 31-36. http://dx.doi.org/10.1007/s13187-014-0678-y

[24] Attallah, M., Hamdan-Mansour, A., Al-Sayyed, M. and Aboshaiqa, A. (2013) Patient Satisfaction with Quality of Nursing Care Provided at Saudi Arabia. International Journal of Nursing Practice, 19, 584-590. http://dx.doi.org/10.1111/ijn.12102

\section{Submit or recommend next manuscript to SCIRP and we will provide best service for you:}

Accepting pre-submission inquiries through Email, Facebook, LinkedIn, Twitter, etc. A wide selection of journals (inclusive of 9 subjects, more than 200 journals)

Providing 24-hour high-quality service

User-friendly online submission system

Fair and swift peer-review system

Efficient typesetting and proofreading procedure

Display of the result of downloads and visits, as well as the number of cited articles

Maximum dissemination of your research work

Submit your manuscript at: http://papersubmission.scirp.org/

Or contact ojn@scirp.org 